\title{
An Object Role Database Model for Enhanced Fuel Distribution and Sales Monitoring in Nigeria
}

\author{
Eke B. O. \\ Department of Computer Science \\ University of Port Harcourt \\ Port Harcourt, Nigeria
}

\author{
Egbono F. \\ Department of Computer Science \\ University of Port Harcourt, \\ Port Harcourt, Nigeria
}

\begin{abstract}
Central to any long - term stability in fuel scarcity is the effective production, distribution and monitoring of petroleum products sales across filling stations by nations with oil subsidy policies. The use of modern information and communication technology (ICT) acts as a facilitator in assisting the monitoring committee and the public in knowing which filling station has been allocated product and the quantity of petroleum product for any given filling station at any given time in the country. This paper, presents an Object Role Model of a highly scalable Distributed Database System designed to accommodate all data entities which include the quantity of fuel usage, number of filling station, quantity of fuel distributed, quantity imported, companies paid subsidy and companies owed. Other entities include quantity of petroleum refined locally and the location of the filling stations allocated. These data entities provide information that the public, fuel marketers, price monitoring team and the government can use in restoring normalcy in the chaotic fuel situation in Nigeria. The system will provide a central communication link among the stakeholders to enhance and facilitate harmony and the overall development of the petroleum sub sector of the national economy.
\end{abstract}

Keywords: Object Role Model, Distributed Database, Petroleum Distribution, Data entities

\section{INTRODUCTION}

An information system is an arrangement of people, data, processes, information presentation, and information technology that interact to support and improve day to day operations in a business as well as support the problemsolving and decision-making needs of management and users [1]. The definition highlighted a major point which is the support for problem-solving and decision-making needs of users.

In this paper, the users of the model are the developers of applications used by the public that consume the petroleum product and the government that need the information to stabilize the petroleum sector. The model supports a database entity technology that can be deployed in the development of information system that can aid several decision processes of fuel marketers and fuel buyers who engage in panic buying at any speculation of scarcity from rumors. Many organizations consider information systems and information technology to be essential to their ability to complete or gain a competitive advantage. Most businesses in their developmental effort and decision making process need to develop information systems by using the data entities in the process of the system development..

In building an information system, the stakeholders in the system need to be known. The stakeholders are the people who have interest in an existing or new information system. Stakeholders can be technical or non-technical and they can be broadly classified into six groups:

i) System owners: They pay for the system to be built and maintained. They own the system, set priorities for the system, and determine policies for its use. In some cases, system owners may also be system users.

ii) System users: They use the system to perform or support their work. They also define the business requirements and performance expectations for the system to be built.

iii)System designers: They design the system to meet the users' requirements. In many cases, these technical specialists may also be system analysts.

iv) System builders or programmers: They program, test, and deliver the system into operation.

\section{ANALYSIS}

The analyses involve the breakdown of conditions and the entities in such a way as to make them ready for use as components in the construction [2] of the fuel distribution and oil sales monitoring system.

\subsection{Present System Analysis}

Presently, Oil Marketers simply quote certain amount of money as their subsidy and the government just has to pay once it is certified by its agents, at least from the point of view of the public. The system could be very good if the government agents in-charge are professional and reliable. But in contrast the government agents could collide with the oil marketers to corruptly enrich themselves but over quoting the amount of money to be paid to get some cut from the marketers. However the system will add transparency to the process by linking the actual quantity of oil in circulation to the subsidy allowing all the stakeholders to estimate the actual subsidy that the government needs to pay.

\subsection{Proposed System Analysis}

There is a need for opening of the way to availability of fuel and the creation of free trade environment for the development of the petroleum industry in Nigeria. However within the subsidy regime there are data components that must be modeled to make the operation as open and efficient as possible via information technology. 
The data components or entities includes [3]:

The quantity of fuel usage: If one asks any government agent the quantity of fuel that is actually used in the country, the answer will be a very bad estimation that will either be in gross excess or in greater underestimation. With this entity a specific figure need to be provided and the figure can be checked against other values from other sources.

Number of filling station: When one moves around the nation there are many filling stations over grown with weeds showing that the filling station may exist only in NNPC papers but on reality does not exist. It is therefore extremely difficult to specify the actual number of filling stations operational in the country especially where some are temporarily or permanently sealed off by agents of government.

iii)

Quantity of fuel distributed: Many filling stations that have fuel on paper are often closed and empty in reality and the fuel loaded for them to sell is diverted to other locations or have left the nation through illegal routes. The actual quantity of fuel in circulation is hardly known by the subsidy payer-government. But the entity offers a figure that can be checked against any other parameters.

Quantity Imported: There are marketers who import product only in paper and as such collect certain amount of money from the government as subsidy for products that may have never existed in the first place. But if the quantity imported entity is specified then the depots that received the oil can easily be tracked to see if the fuel is actually on ground as shown by the system.

Companies paid subsidy: The companies that actually imported product must be the companies receiving subsidy and the money paid to them should be well specified so that it will be easy to know the exact outstanding fund so that the fire bridge approach of handling payment can be easily eliminated. Recently subsidy funds are released only when marketers go on strike or threaten to do so.
Companies owed: The companies that are being owed need to be listed so that the companies will know that the government is aware of the debt and that they have intension to pay. The public will also expect the companies to either be patient or opt out of the subsidy system.

Quantity of petroleum refined locally: The quantity of petroleum product needed to be imported can easily be computed if the quantity used are known and the quantity refined locally are known. The balance can easily be calculated and decision on how much is needed to be imported and pay for subsidy can be planned ahead and captured in the budget of the country for each year.

These data entities provides information that the public, fuel marketers, price monitoring team and the government can use in restoring normalcy in the chaotic fuel situation in Nigeria. The system will provide a central communicative link among the stakeholders to enhance and facilitate harmony and the overall development of the petroleum subsector of the national economy.

The entities will form the core of the database structure of the system to be developed for the petroleum subsector harmonization. The entities name may vary from one developer to another but the content may still remain the same. These entities are essential for the design stage of the database development required in the system development. It is also note worthy that the entities listed here are not necessarily the only entities required but are the major ones required.

\section{DATABASE DESIGN}

In the table 1 below the entities that are needed for the database are represented using their names, the entities types, there descriptions and the length.

The database record of the fuel activities listed in table 1 is described below to provide further clarification which includes:

1) The serial number which can be used as a primary key for the database

2) The ability of identifying an individual fuel user is really a challenge and by extension the total number of fuel used in Nigeria. This is more challenging with illegal importation and illegal refining activities which add to the level of unaccounted fuel available in the nation. However ignoring theses sources and further blocking smugglers activities will provide a reasonable solution.

3)

Number of filling station: The ability to record the functional filling stations and update the record when ever new licenses are granted for opening a new one is needed. Whenever a company opens another branch of their filling station the record must be updated. Since filling stations are physical it may be easier to get the data.

4)

Quantity of fuel distributed: The filling stations needed to be modernized so that all fuel pumped can be recorded and automatically captured by the central system. This can be carried out by recommending modern electronic pump machines which can record and transfer the data to filling stations.

5)

Quantity imported: The nature of import and discharge of fuel in the sea ports makes it very easy to record the quantity of fuel imported so that the trend of importation can be easy to record.

6)

Companies paid subsidy: The Oil Companies that have been paid subsidy are listed with this field. The field 
will help in knowing the budget required to pay subsidy ahead of time. The companies paid will also not have the opportunity to complain hiding on the shadow of the companies still owed.

7)

Companies owed: The companies that have not being paid also needed to be listed under this field to offer this companies hope of payment and possibly the dates that payments are expected to be made. This helps the companies to sale on the normal price while waiting for payment.

8)

Quantity of petroleum refined locally: The figures can be easily generated from all the refineries in the country. The figures are necessary to know the increase and decrease in refined product and the actual quantity needed to be imported.

\subsection{Database Table Structure}

In the design of the database there is a need to develop the table structure by extracting the possible fields expected from the database [4]. These fields are made of the names that are necessary for use in identifying the set of data needed to be presented in the database. The fields are supposed to keep data in the database with specific type which is usually specified in the entity type field. The field detail are also specified in the field description column and the length of each of the field is specified.

In table 1sample fields from different tables where illustrated using some of the important fields relating to the topic of discuss-oil sales monitoring in a subsidy country or regime. The table illustrate the field names, the entity types, the entity description and the length of the field. In real life DBMS the table description may vary slightly.

Table 1: Structure of Needed Database Files

\begin{tabular}{|c|c|c|c|c|}
\hline $\begin{array}{c}\text { SN } \\
\text { O }\end{array}$ & $\begin{array}{c}\text { Field/Entity } \\
\text { Names }\end{array}$ & $\begin{array}{c}\text { Entity } \\
\text { Types }\end{array}$ & $\begin{array}{c}\text { Entity } \\
\text { Description }\end{array}$ & Length \\
\hline $\mathbf{1}$ & $\begin{array}{c}\text { Qty_Fuel_ } \\
\text { Use }\end{array}$ & Number & $\begin{array}{c}\text { The quantity of } \\
\text { fuel usage } \\
\text { of the Records }\end{array}$ & \\
\hline $\mathbf{2}$ & $\begin{array}{c}\text { Filling_Sta } \\
\text { t_No }\end{array}$ & Number & $\begin{array}{c}\text { Number of } \\
\text { filling station: }\end{array}$ & \\
\hline $\mathbf{3}$ & $\begin{array}{c}\text { Qty_Fuel_ } \\
\text { Distr }\end{array}$ & Number & $\begin{array}{c}\text { Quantity of } \\
\text { fuel } \\
\text { distributed: }\end{array}$ & \\
\hline $\mathbf{4}$ & $\begin{array}{c}\text { Qty_Fuel_I } \\
\text { mported }\end{array}$ & Number & $\begin{array}{c}\text { Quantity } \\
\text { imported: }\end{array}$ & \\
\hline $\mathbf{5}$ & $\begin{array}{c}\text { Companies } \\
\text { Paid }\end{array}$ & String & $\begin{array}{c}\text { Companies } \\
\text { paid subsidy: }\end{array}$ & \\
\hline $\mathbf{6}$ & $\begin{array}{c}\text { Companies } \\
\text { _Owed }\end{array}$ & String & $\begin{array}{c}\text { Companies } \\
\text { owed: }\end{array}$ & \\
\hline $\mathbf{7}$ & $\begin{array}{c}\text { Qty_Refine } \\
\text { d }\end{array}$ & Number & $\begin{array}{c}\text { Quantity of } \\
\text { petroleum } \\
\text { refined locally: }\end{array}$ & \\
\hline
\end{tabular}

\subsection{Entity-Relationship Conceptual Design}

In other to depict the characteristics of database distributable over many sites, let us consider a particular case used for this research. We begin with a Government Fuel sales Monitoring/ Fuel Usage database. The database entities are illustrated in

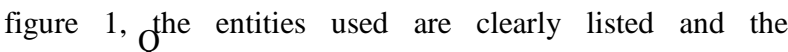
relationship expected to bind the data is also illustrated. The entities include quantity of fuel used (Qty_fuel_used), Number of Filling station (Fillng_Stat_No) and with the input of Government, oil marketers and data gathering organizations. The databases interrelate with one another in various ways however this relationships can be represented as an entity-relationship diagram.



Fig 1: Depiction of an Fuel Monitoring Database

A fuel monitoring database for the system contains data about fuel usage, import distributions and other parameters that are already listed and required in keeping petroleum distribution and pricing stable across the nation. The Organizations that will gather the data, government, monitoring agents and the oil marketers are also captured in the system. The design presented however is the conceptual design and not the detail design of the system. The detail ERD design is presented in the next section. The implementation of the database may be at different locations or different Network servers but due to their relationship, many entities can be fetched, joined and used in generating answers to various kinds of questions which ordinarily would have been difficult to answer without the distributed database [5]. 


\subsection{Design View and Integration}

The distributed database is not generated at a single site, therefore it can be classified as large and complex [5]. Therefore, there must be a way to manage the complexity of the design process. Design View and integration can be used in managing the fuel monitoring and usage database design project by providing a way to break a large effort into smaller parts. In these cases, we combine individual views into a complete database design.

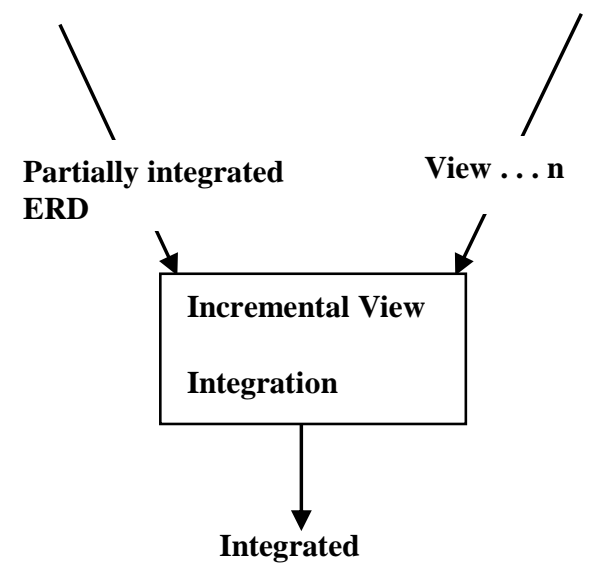

\section{Fig 2: Incremental Integration Design}

In Figure 2, a view and a partially integrated Entity Relationship Design (ERD) are merged in each Integration step. Initially, we choose a view and contracts on ERD for it. For instance, filling stations can comprise fuel consumers and oil Marketers data on fuel sales, fuel bought and fuel supplied ; these can be different views of the same database. Each view has a different ERD and is incremented as a partially integrated ERD produced after each step. The approach can be binary as the current view is analyzed along with the partially integrated ERD or multiple views. ERDs are produced for each view and then the view ERDs are merged. The integration occurs in one large step after all views are analyzed. This approach is parallel because different designers can perform view designs at the same time.

In this approach we postponed integration until the end when all views are integrated to produce the final ERD. The incremental approach [5] is well suited for the implementation in this work because of closely related views. For example, the fuel importation, fuel usage, filling station and subsidy payments are closely related, because importation precedes payment and availability in filling station which influences fuel usage.

\section{Entity-Relationship Detail Design}

In the detail design of the ERD design presented in figure 3 the Oil filling station is related to the Consumers table by sales of fuel. The relationship is defined as one or more oil filling stations relating to one or more fuel consumers. This relationship is clearly illustrated. On the other hand the Oil depot supplies oil to the oil filling stations and the relationship is clearly shown as non or more depot to oil filling station relationship. This indicate that all fuel supplied at filling stations do not necessarily originate from depots others may be direct shipment from refineries to the filling stations.

In figure 3, the relationship of oil monitors and oil filling station clearly shows a one to many relationship where one filling station get checked by one or many monitoring agents and many filling station also get checked by one or more monitoring agents using check compliance from the monitor. Here the rules and price limits for the sale of the product is being monitored to ensure that filling stations complied to the regulations specified. The relationship between importers and oil depots is also clear, importers ship their imported fuel to oil depots from where they are supplied to the oil filling stations. The oil depots in turn expect to get oil from the importers.

In Nigeria, importation of oil is handled by independent oil marketers and the nations oil company -Nigerian National Petroluem Company (NNPC). The percentage of importation usually vary from 50-50, 30-70 and even 0-100 depending on policy of the day and the availability of foreign exchange for importation of mostly refined product. Unlike many developed and developing nations, Nigeria exports crude and imports refined product since its locally refine product could not sustain local usage at least as at the time of this publication. However, if all the product are refined locally the situation may remain the same if the subsidy regime persists. The Department for Petroluem Resources (DPR) is saddled with the responsibility of monitoring the sales of petroleum products at government approved price.

In the entity relationship diagram it is equally clear that the relationship between the Independent (Ind) marketers and the importers of fuel are demonstrated. The independent marketers import oil and therefore are importers and share data and information with the importer database. 


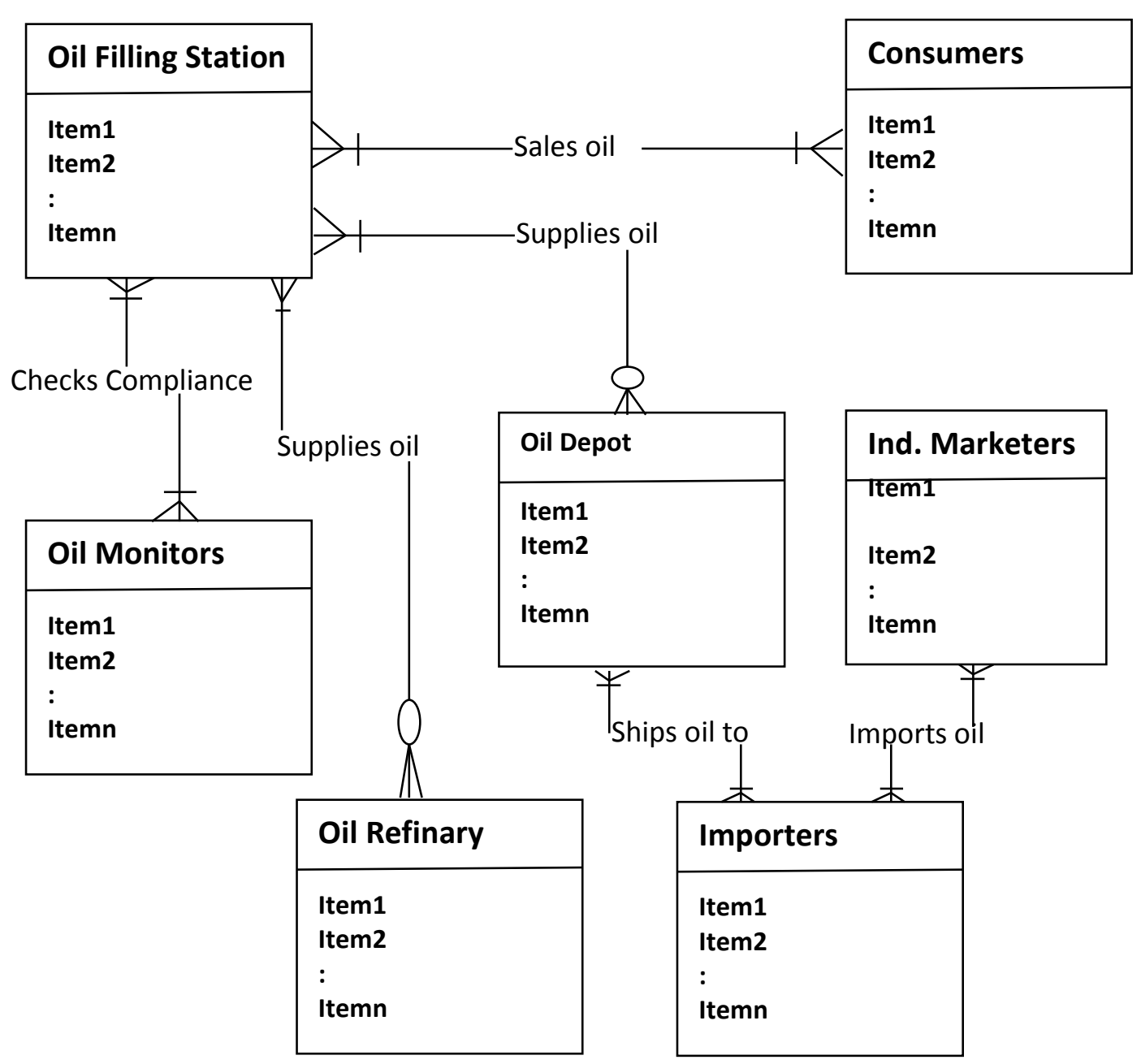

Fig. 3: The Entity Relationship Diagram of the Distributed Database of Oil Sales Monitoring System.

\section{OBJECT ROLE MODEL DESIGN}

Object Role Model (ORM) is a design system at the conceptual level and mapping between conceptual and logical (e.g. relational) levels, where the application is described in terms readily understood by users, rather than being recast in terms of implementation data structures. ORM includes a formal, textual specification language for both models and queries, as well as a formal, graphical modeling language [6].

Object Role Modeling got its name based on its views of the application world as a set of objects (entities or values) that plays roles (parts in relationships). It is sometimes called factbased modeling because ORM verbalizes the relevant data as elementary facts. These facts cannot be split into smaller facts without losing information.
Object role modeling recognizes four basic kinds of data objects: simple, value, composite, and nested. A simple object is one in which real world instances are designated -- uniquely identified -- by a single data element; i.e., a single data element comprises the primary key [7]. Figure 4 shows how oil filling station would be represented in an object role model when real-world filling stations are to be designated in the database by an identifying number, Station_id, rather than by their names. Here, an oil Filling station is an example of a simple object.

The ORM model design of the fuel distribution and fuel sales monitoring system is presented in figure 4 using an Object Role Modeling technique. This design makes it easy to understand the movement of data activity and interaction between objects without presenting the detail data components of the objects. 


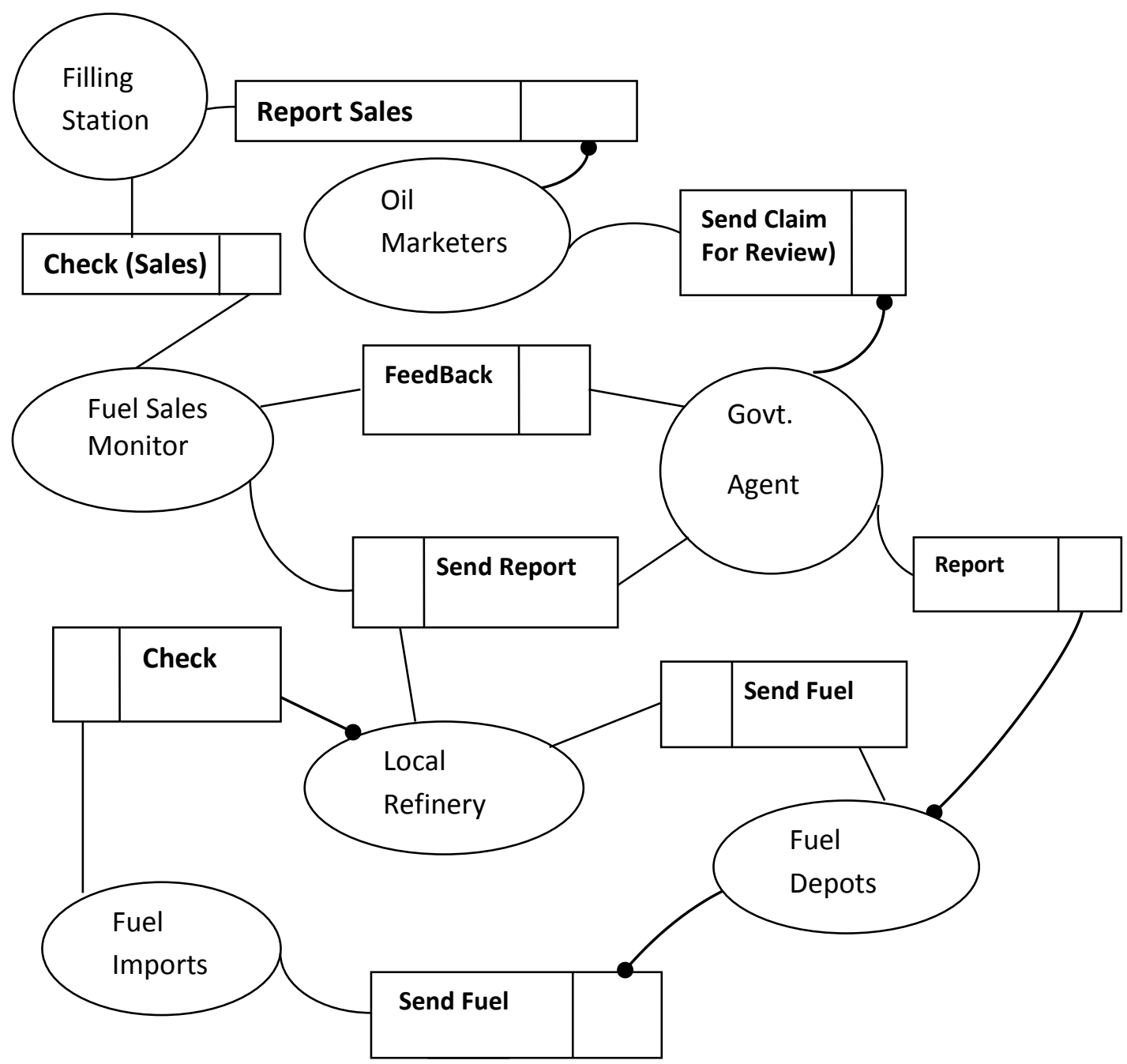

Fig 4: Design of the Object Role Database Model using ORM

A value object is something like a name (label), number, or date, which represents a simple scalar attribute [8]. Fuel Depots in Figure 4, is a value object. It is clear from the object-oriented perspective that an object- Fuel Imports is distinctive from Fuel Depots yet there is a relationship. It is shown from the model that Send Fuel links the two distinct objects since fuel imports (imported fuel) are sent to fuel depots. When simple and value objects are combined using a key, composites are formed. An object whose existence and identity stems from the relationship between two other objects is called a nested object. A "circle" (a rectangle with rounded corners) is drawn around the relationship to "objectify" it. A nested object can then participate in relationships with other objects [9].
In figure 4, several relationships exit between various objects within the object-role model. This relationships include report sales connecting the oil marketers and the filling stations, check sales connecting the fuel sales monitors and the filling stations, and send claim which links the oil marketers and the Government agent responsible for payment of subsidy claims. Other relationships include feedback connecting the fuel sales monitors (DPR in Nigeria) with the Government agent incharge, report linking the fuel depots and the Government agent, send fuel linking the depots and the local oil refinery and check connecting fuel imports and the local refinery. This relationships are easy to understand by both the developers and the requirement specifier or system owner. 
The object-Role Model design presented in this work serves as an easy pedestal for the application developers or the programmers to leverage in the implementation of the system devoid of details of the each database. This makes the system adaptable to various implementation for a particular country based on the actual data available on fuel subsidy in the country. The model can also be applied in process to process assessment of the system before commitment can be made on implementation.

\section{CONCLUSIONS}

In Nigeria a lot of effort has been made to improve the fuel supply with mixed success. There is the need to develop a system that will guide the Government authorities, Independent Petroleum Marketers Association of Nigeria (IPMAN)- oil marketers, Department of Petroleum Resources (DPR)- fuel monitors and other stakeholders in the distribution of fuel in Nigeria. In the first instance, we need to design the system before its implementation. In this paper, the Object Role Model has been designed for the system for monitoring fuel sales by conceptualizing the system, producing the Entity relationship and using the entities in the development of the ORM for the system. The developed system can be implemented based on the policy of the government on fuel subsidy at any given time. In Nigeria, Government and Independent Marketers jointly import subsidized refined products at varying ratios, such as 50-50, 70-30 and even 100-0 for government against marketers. At 50-50 the government oil company -NNPC imports 50\% of the product while marketers imports $50 \%$. At $100-0$, only the imported fuel of NNPC is subsidized, if the marketers import fuel their fuel imports are not subsidized at all. It shows from the design that the implementation is expected to follow the policy being carried out at a given time.

\subsection{Recommendation}

In this paper, the users of the model are the developers who implements the system for fuel sales monitoring either from the government or from the independent marketers. The government need the implemented system to stabilize the petroleum distribution challenge in Nigeria. The model will offer a database entity technology that can be deployed in the development of information system that can aid several decision processes of fuel marketers and fuel buyers who engage in panic buying at any speculation of scarcity from rumors. The government can also use the system to reduce subsidy misunderstanding and mis-information between government, the public and oil-marketers.

Model designers who want to develop other systems in information technology using Object Role Modeling technique will find the work in this paper useful, since it is simple and direct to the application area. The designers can derive inspiration from the work in analyzing their systems and from the entities of that particular system design the ORM model which can be useful in the development of their systems.

The model designed in this paper can be easily modified for application in other related areas involving government subsidies [11] such as Bread Subsidy (in Egypt), feeding subsidy (in India), agricultural subsidy (in USA) and other government subsidies in other countries.

\section{ACKNOWLEDGMENTS}

Thanks to Oyol Computer Consult, Inc Port Harcourt, Nigeria for supporting the research in the time when power and petroleum scarcity seem to be most critical in Nigeria. We also expect their contribution in the implementation of the model designed in this research.

\section{REFERENCES}

[1] Forouzan B. A. and Fegans, S. C (2005) Data Communicational and Networking, Tata McGraw-Hill Publishers Companies Ltd New Delhi 11008, (2005). 8-9, (Third Edition), Website: www.tatamcgrawhill.com.

[2] Pratt, Philip J., and Adamski, Joseph J.,(1991) Database Systems - Management and Design, 2nd Edition, Boyd and Fraser, 1991.

[3] Adeniyi G. (1997): “The Impact of Oil Exploration and Production Activities on the Environment: Implications for Peasant Agriculture" Seminar Paper on Oil and The Environment organized by Friedrich Ebert Foundations in Port Harcourt.

[4] Kossmann D., (2000).The State of Art in Distributed Query Processing. ACM Computing Surveys. Volume 32, No 4 December pp 422-469

[5] Gupta, A. (2009). Database Management System in the Practical Approach to SQL \& PL/SQL. Daryaganj Delhi: S. K. Kataria \& Sons.

[6] Terry Halpin (2012) Object-Role Modeling (ORM/NIAM), Microsoft Corporation, USA reproduced by permission.from Handbook on Architectures of Information Systems, eds P. Bernus, K. Mertins \& G. Schmidt, Springer-Verlag, Berlin, 1998, www.springer.de/cgi-bin/search_book.pl?isbn=3-54064453-9.

[7] Stanley D. B. (2015) A Primer on Object Role Modeling, University of California Press,Berkeley, USA, accessed 2015

[8] Garvey, M. A., and Jackson, M. S. (2010), " ObjectOriented Databases", Information and Software Technology, Vol. 31, No. 10, pp524-525 Dec. 2010. 
[9] Akash M. (2012)Classifying data for successful modeling, http://www.dwbiconcepts.com/data-warehousing/12-datamodelling/101-classifying-data-for-successful-modeling.html

[10] Gourevitch, P. 1986. Politics in Hard Times :

Comparative Responses to International Economic

Crises. Ithaca: Cornell University Press.

[11] Beñat B., Soumitra D., and Bruno L. 2013 The Global Information Technology Report 2013, Growth and Jobs in a Hyperconnected World, Pulished by World Economic.

\section{ABOUT THE AUTHORS}

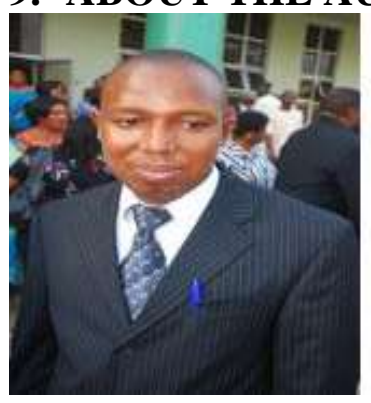

Dr. Eke Bartholomew is a Software Engineering Lecturer in Uniport and visiting Instructor at Institute of Petroluem Studies UPH. His research interest is in SE Methodologies and System Devepolment. He has numerous publications in Nigeria and across the Globe.

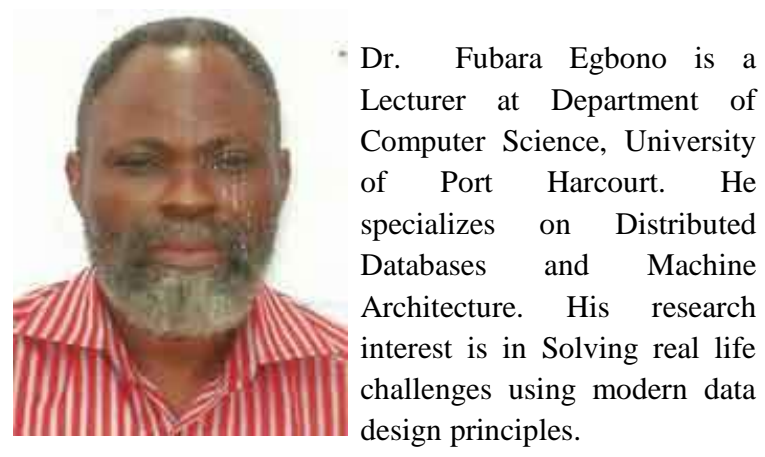

